\title{
Relationships of Condylar Path Angle with Malocclusion and Temporomandibular Joint Disturbances
}

\author{
Mitsuru MOTOYOSHI, Kiichiro INOUE, Kazuhiro KIUCHI, \\ Masae OHYA, Akira NAKAJIMA, Toshiaki ARAMOTO \\ and Shinkichi NAMURA
}

(Received 17 February and accepted 29 October 1992)

Key words: condylar path angle, axiographic tracing, malocclusion, temporomandibular joint

\begin{abstract}
A study was conducted to investigate the condylar path angle in relation to Angle's classification, amount of overbite and subjective symptoms. The condylar path angle in Angle's Class I group was similar to that in the Class II group. The angle in the Class III group was smaller than in the other two classes. A tendency for the angle to decrease as the amount of overbite became smaller was observed. The angle in the symptom group was slightly smaller than in the no-symptom group.
\end{abstract}

\section{Introduction}

Condylar path movement is thought to be closely related to occlusal function. Axiographic protrusive curves traced by hinge-axis reveal the movement of the condyle. The shape and range of movement of the axiographic tracings are useful when diagnosing temporomandibular joint dysfunction (TMD). However, the condyle fulfills its function within the limits of a few millimeters from the centric occlusion (CO) or the centric relation (CR) during masticatory movement, especially when food is broken into fragments. The characteristics of the axiographic protrusive curves on the beginning point, $\mathrm{CO}$ or $\mathrm{CR}$, and its environs are expected to be relevant to functional occlusal contacts and/or TMD. In order to clarify these interrelationships, it is necessary to examine the initial condylar movement instead of condylar movement capacities such as maximum opening capacity, and to investigate the connection between the initial inclination and the occlusal state. The relation between jaw movement and malocclusion has been investigated by many researchers. A considerable number of investigations have focused on mandibular movement capacities ${ }^{[1-3]}$. However, there have been only a few studies on the initial inclination of axiographic tracings ${ }^{[4]}$.

In this study, we measured the initial inclinations of axiographic protrusive curves using adult subjects, and investigated their relationship with Angle's classification and the amount of overbite. The relation between hinge-axis guidance and the occurrence of symptoms was also considered.

\section{Materials and Methods}

Subjects were selected from 151 non-orthodontically treated students at Nihon University School of Dentistry. First, axiographic tracings of 80 subjects were recorded using a computer-

本吉 満, 井上貴一朗, 木内一弘, 大矢方恵, 中嶋 昭, 新本俊影, 納村晉吉

Department of Orthodontics, Nihon University School of Dentistry, 1-8-13, Kanda-Surugadai, Chiyoda-ku, Tokyo 101, Japan

Part of this paper was presented at the 50th annual meeting of the Japan Orthodontic Society in Osaka, September, 1991

To whom all correspondence should be addressed: Dr. Mitsuru MOTOYOSHI, Department of Orthodontics, Nihon University School of Dentistry, 1-8-13, Kanda-Surugadai, Chiyoda-ku, Tokyo 101, JAPAN 


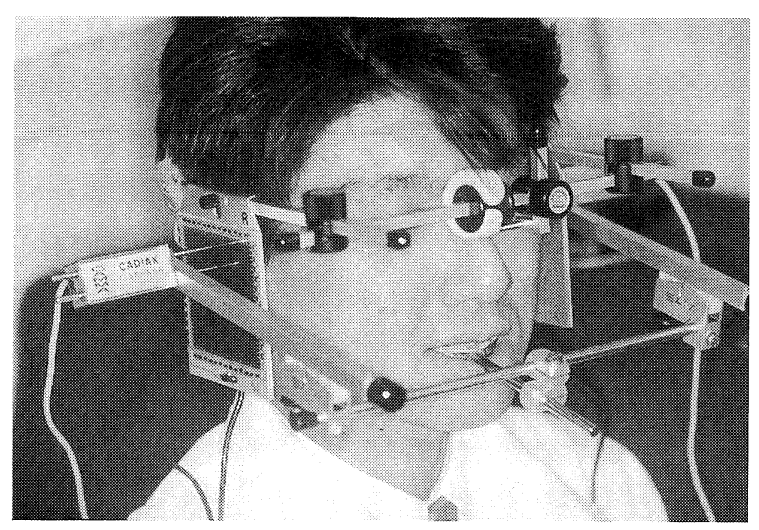

Fig. 1 The SAM axiographic registration device (CADIAX)

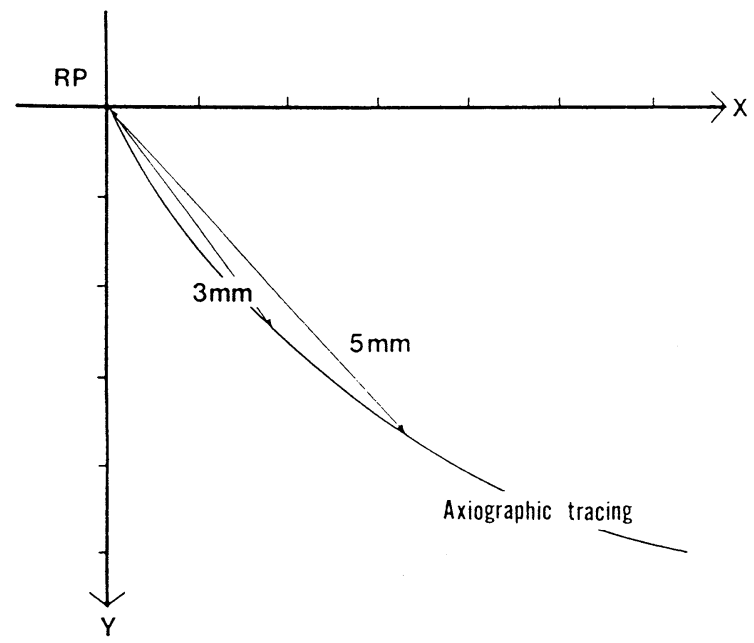

Fig. 2 Condylar path angles determined at points $3 \mathrm{~mm}(3 \mathrm{~mm}$ angle) and $5 \mathrm{~mm}(5 \mathrm{~mm}$ angle $)$ from the reference point (RP)

Table 1 Sagittal condylar path angle in each group divided by Angle's classification

\begin{tabular}{|c|c|c|c|c|c|c|c|c|c|c|}
\hline & & $3 \mathrm{~mm} /$ angle & sig. & & $5 \mathrm{~mm} /$ angle & sig. & & mean/angle & sig. & \\
\hline Class I & $\begin{array}{c}\text { MEAN } \\
\text { S.D. }\end{array}$ & $\begin{array}{r}62.6 \\
6.0\end{array}$ & \multirow[b]{2}{*}{$1 \%$} & \multirow{3}{*}{$1 \%$} & $\begin{array}{r}62.8 \\
5.3\end{array}$ & & \multirow{3}{*}{$1 \%$} & $\begin{array}{r}62.7 \\
5.6\end{array}$ & \multirow{3}{*}{$1 \%$} & \\
\hline Class II & $\begin{array}{c}\text { MEAN } \\
\text { S.D. }\end{array}$ & $\begin{array}{r}61.5 \\
5.0\end{array}$ & & & $\begin{array}{r}63.2 \\
4.2 \\
\end{array}$ & $1 \%$ & & $\begin{array}{r}62.4 \\
4.3\end{array}$ & & $1 \%$ \\
\hline Class III & $\begin{array}{c}\text { MEAN } \\
\text { S.D. }\end{array}$ & $\begin{array}{r}55.9 \\
5.9\end{array}$ & & & $\begin{array}{r}56.8 \\
5.5\end{array}$ & & & $\begin{array}{r}56.3 \\
5.6\end{array}$ & & \\
\hline
\end{tabular}

unit : degree 
Table 2 Sagittal condylar path angle in each group divided by amount of overbite

\begin{tabular}{|c|c|c|c|c|c|c|c|}
\hline & & $3 \mathrm{~mm} /$ angle & sig. & $5 \mathrm{~mm} /$ angle & sig. & mean/angle & sig. \\
\hline group 0 & $\begin{array}{c}\text { MEAN } \\
\text { S.D. }\end{array}$ & $\begin{array}{r}57.9 \\
4.2\end{array}$ & \multirow[t]{4}{*}{$1 \%$} & $\begin{array}{r}60.3 \\
3.5\end{array}$ & \multirow{4}{*}{$5 \%$} & $\begin{array}{r}59.1 \\
3.6\end{array}$ & \multirow[t]{4}{*}{$1 \%$} \\
\hline group 1 & $\begin{array}{c}\text { MEAN } \\
\text { S.D. }\end{array}$ & $\begin{array}{r}61.5 \\
5.3\end{array}$ & & $\begin{array}{r}61.9 \\
5.4 \\
\end{array}$ & & $\begin{array}{r}61.7 \\
5.3 \\
\end{array}$ & \\
\hline group 2 & $\begin{array}{c}\text { MEAN } \\
\text { S.D. }\end{array}$ & $\begin{array}{r}62.9 \\
6.0\end{array}$ & & $\begin{array}{r}62.6 \\
5.2\end{array}$ & & $\begin{array}{r}62.8 \\
5.5\end{array}$ & \\
\hline group 3 & $\begin{array}{c}\text { MEAN } \\
\text { S.D. }\end{array}$ & $\begin{array}{r}62.9 \\
5.1\end{array}$ & & $\begin{array}{r}64.9 \\
3.9\end{array}$ & & $\begin{array}{r}63.9 \\
4.3\end{array}$ & \\
\hline
\end{tabular}

unit : degree

Table 3 Sagittal condylar path angle in symptom and no-symptom group

\begin{tabular}{l|c|c|c|c}
\hline \multicolumn{2}{l}{} & $3 \mathrm{~mm} /$ angle & $5 \mathrm{~mm} /$ angle & mean/angle \\
\hline \multirow{2}{*}{ symptom group } & MEAN & 62.3 & 62.2 & 62.3 \\
& S.D. & 8.6 & 6.7 & 7.6 \\
\hline \multirow{2}{*}{ no-symptom group } & MEAN & 59.7 & 60.6 & 60.2 \\
& S.D. & 6.7 & 6.4 & 6.4 \\
\hline sig. & $5 \%$ & & $10 \%$ \\
\hline \multicolumn{2}{l|}{ unit : degree }
\end{tabular}

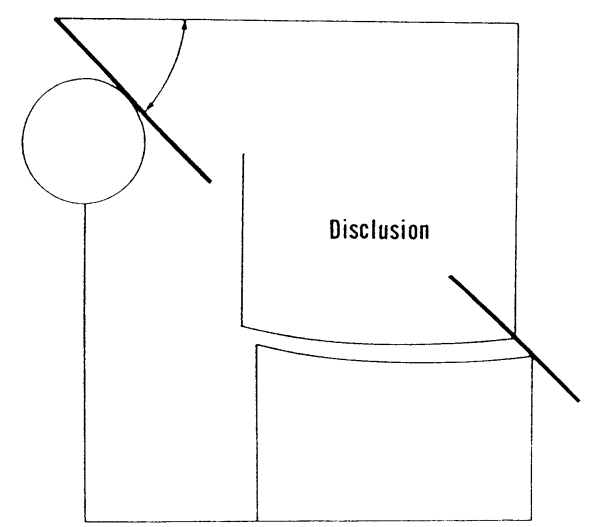

Fig. 3 Adequate inclination of posterior guidance creates disclusion. 


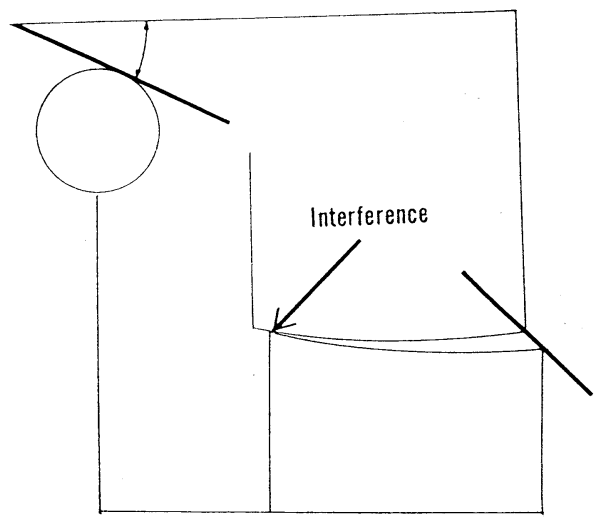

Fig. 4 Occlusal interference is often produced when the condylar path angle is too small.

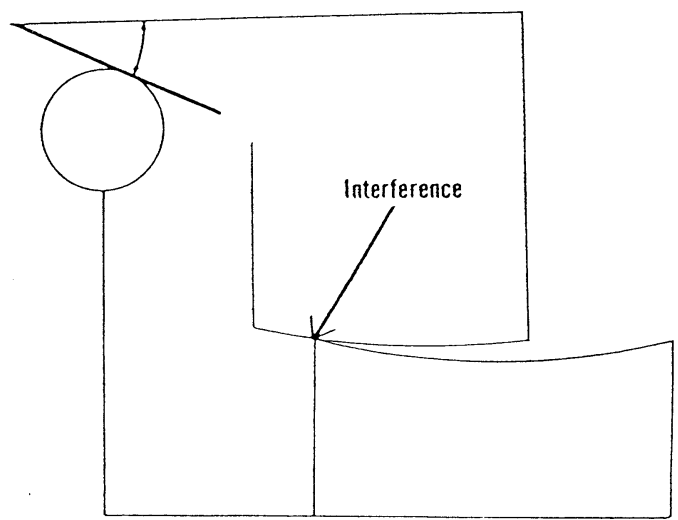

Fig. 5 Anterior crossbite gives rise to posterior interference.

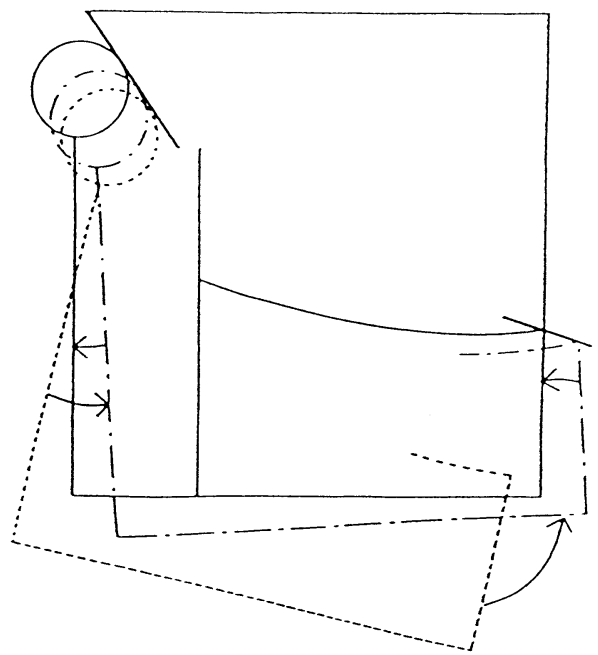

Fig. 6 When posterior guidance steepens to excess, the condyle does not harmonize with its motion; the revolving direction of the condyle is reversed during late closing. 
aided axiograph (Fig. 1). These subjects had an anamnestic dysfunction index ${ }^{[5]}$ of AiO (subjectively symptom-free) or AiI (mild symptoms). Sixty-one subjects without missing teeth except third molars and without any cusps covering prostheses were then selected. No doubtful views with regard to luxation of discs were observed on the axiographic tracing of any subjects. The subjects comprised 42 males and 19 females, aged 23 years 10 months on average.

Initially, the subjects were divided into three groups according to Angle's classification, and the initial inclination was measured in each group. Next, the condylar path angle in each group, divided into the following sets, was measured.
group 0 anterior open bite
group 10 to $1 \mathrm{~mm}$ overbite
group 21 to $5 \mathrm{~mm}$ overbite
group 3 deep bite exceeding $5 \mathrm{~mm}$

Then, with regard to subjective symptoms, the subjects were divided into two groups. The individuals were questioned about TMD such as pain, sense of incompatibility and discomfort of the temporomandibular joint girth. We defined subjects who had any complaints, including mild symptoms ${ }^{[5]}$, as the symptom group, and the others as the no-symptom group.

The reference point was fixed at $\mathrm{CO}$ before measurement. The angle to axis-orbitale plane was calculated at points $3 \mathrm{~mm}$ ( $3 \mathrm{~mm}$ angle) and $5 \mathrm{~mm}$ ( $5 \mathrm{~mm}$ angle) from the reference point on the axiographic protrusive curve (Fig. 2).

\section{Results}

The sagittal condylar path angles in the three groups divided by Angle's classification are shown in Table 1. Axiographically, it was found that $3 \mathrm{~mm}$ angle, $5 \mathrm{~mm}$ angle and the average of $3 \mathrm{~mm}$ and $5 \mathrm{~mm}$ angle (mean angle) in the Class I group were similar to those in the Class II group; approximately 62 to 63 degrees. The angles in the Class III group were significantly smaller than in Class I and Class II $(\mathrm{P}<0.01)$. The angle of each group divided by the amount of overbite is shown in Table 2. A tendency of the angle to decrease as the amount of overbite became smaller was observed. Especially, $3 \mathrm{~mm}$, and mean angle revealed significant differences at the $1 \%$ level between group 0 and group 1 . Results in the symptom and no-symptom groups are shown in Table 3 . The angle in the symptom group was smaller than in the no-symptom group ( $\mathrm{P}<0.05$ : $3 \mathrm{~mm}$ angle, $\mathrm{P}<0.1$ : mean angle).

\section{Discussion}

Keller And CARANO ${ }^{[6]}$ measured inclinations of the eminence on lateral cephalometric $\mathrm{X}$-ray films. However, these inclinations do not reflect the functional movement of the condyle because the shape of the eminence does not always correspond to the tracings of hinge-axis movement. Moreover, measurement error is unavoidable with the X-ray method. To obtain data on functional condylar movement, a computer-aided axiograph (CADIAX) was used in this study. The obtained axiographic tracing represents the actual movement of an individual hinge axis point. When food is broken into fragments, the condyle functions within a range of a few millimeters from the start point. Therefore, assessments were performed using $3 \mathrm{~mm}$ and $5 \mathrm{~mm}$ angles.

According to the results we obtained, the same observations could be made in the initial part of Class I and Class II tracings. However, the initial inclination in Class III was smaller than in Class I and Class II. These findings are similar to data reported by $\mathrm{ZIMMER}^{[4]}$, SCHREMS ${ }^{[7]}$ and $\mathrm{OTT}^{[8]}$. It seems that there are some correlations with the anterior guidance.

Axiographic tracings show that there is a tendency for the initial inclinations to decrease as the amount of overbite becomes smaller. Especially, $3 \mathrm{~mm}$ and mean angle revealed significant differences at the $1 \%$ level between the open bite group and the edge-to-edge bite group. This observation seems to be relevant to the relationship between the anatomical characteristics of 
anterior teeth and the posterior guidance of the condyle. Mandibular movement is determined by the temporomandibular joint posteriorly and the incisal teeth anteriorly. Patterns of mandibular movement are affected by anatomical morphology with regard to posterior guidance and anterior guidance ${ }^{[9]}$. The present results seem to suggest a relationship between the anterior and posterior factors.

Our findings showed a tendency for the initial inclinations, $3 \mathrm{~mm}$ and mean angle to be smaller in the symptom group than in the no-symptom group. This observation can be explained by a disorder of the control mechanism of the anterior and posterior factors. The steepness of the posterior control factor could result in molar disclusion (Fig. 3). However, when the condylar path angle is too small, it often causes occlusal interference in the posterior teeth (Fig. 4). Deficiencies in anterior guidance also give rise to posterior interference (Fig. 5). On the other hand, when the posterior guidance is too steep, the condyle does not show harmony with its motion (Fig. 6). Both control factors function together to define jaw movement.

Among epidemiologic studies investigating the rate of incidence of TMD, $\mathrm{ZARB}^{[10]}$ reported that $61 \%$ of subjects who had TMD showed some form of occlusal discrepancy, suggesting that there are connections between TMD and malocclusion. A number of researchers ${ }^{[11-14]}$ have commented that a divergence between $\mathrm{CO}$ and $\mathrm{CR}$ associated with malocclusion causes TMD. SOLBERG $^{[11]}$ and REIDER ${ }^{[12]}$ suggested that TMD might be caused by occlusal interference in balancing sides. We think there is a close connection between TMD and an imbalance which exists between the anterior control factor, including canine guidance, and the posterior control factor. The anterior control factor can easily be changed by orthodontic treatment. Alteration of this factor seems to play an important part in treatment, even in the occurrence of masticatory dysfunction.

\section{References}

[1] Ingervall, B.: Variation of the range of movement of the mandible in relation to facial morphology in children, Scand. J. Dent. Res., 78, 535-543, 1970

[2] Ingervall, B.: Variation of the range of movement of the mandible in relation to facial morphology in young adults, Scand. J. Dent. Res., 79, 133-140, 1971

[3] Wisth, P. J.: Mandibular function and dysfunction in patients with mandibular prognathism, Am. J. Orthodont., 85, 193-198, 1984

[4] Zimmer, B., Jager, A. and Kubein-Meesenburg, D.: Comparison of normal TMJ function in Class I, II, and III individuals, Eur. J. Orthodont., 13, 27-34, 1991

[5] Нецкімо, M.: Studies on function and dysfunction of the masticatory system, Swed. Dent. J., 67, 101-121, 1974

[6] Keller, D. C. and Carano, A.: Eminence-posterior occlusal plane angle in patients with temporomandibular disorders, J. Craniomandibular Pract., 9, 159-163, 1991

[7] Shrems, H-Th.: Pantografishe untersuchungen in der kieferirhotpadie, Dtsch. Zahnärztl. Z., 32, 93-95, 1977

[8] Отт, K.: Kiefergelenkfunktion, Carl Hanser Verlag, München, 1982

[9] Okeson, J. P.: Management of Temporomandibular Disorders and Occlusion, 2nd Ed., C. V. Mosby Co., St. Louis, U. S. A., 1989

[10] Zarb, G. A. and Thompson, G. W.: Assessment of clinical treatment of patients with temporomandibular joint dysfunction, J. Prosthet. Dent., 24, 542-554, 1970

[11] Solberg, W. K., Woo, M. W. and Houston, J. B.: Prevalence of mandibular dysfunction in young adults, $J A D A, 98,25-34,1979$

[12] Reider, C. E., Martinoff, J. T. and Wilcox, S. A.: The prevalence of mandibular dysfunction. Part I: Sex and age distribution of related signs and symptoms, J. Prosthet. Dent., 50, 81-88, 1983

[13] Hanson, T. and Nilner, M.: A study of the occurrence of symptoms of diseases of the temporomandibular joint, masticatory musculature and related structures, J. Oral Rehabil., 2, 313-324, 1975

[14] Agerberg, C. and Carlson, G. E.: Functional disorders of the masticatory system. I. Distribution of symptoms according to age and sex as judged from investigation by questionnaire, Acta Odontol. Scand., 30, 597-612, 1972 